\title{
Guidelines for ${ }^{18}$ F-FDG PET and PET-CT imaging in paediatric oncology
}

\section{J. Stauss • C. Franzius - T. Pfluger - K. U. Juergens • \\ L. Biassoni - J. Begent $\cdot$ R. Kluge $\cdot$ H. Amthauer \\ T. Voelker • L. Højgaard • S. Barrington • S. Hain • \\ T. Lynch • K. Hahn}

Published online: 26 September 2008

(C) Springer-Verlag 2008

\section{Erratum to: Eur J Nucl Med Mol Imaging}

(2008) 35:1581-1588

DOI 10.1007/s00259-008-0826-x

In the original publication the affiliations of the co-author Christiane Franzius were incomplete. Her full affiliations are as given here.

Department of Nuclear Medicine, University Hospital Muenster, Muenster, Germany

MR and PET/CT-Centre Bremen-Mitte, Bremen, Germany

The online version of the original can be found at http://dx.doi.org/ 10.1007/s00259-008-0826-x.

J. Stauss $(\bowtie)$

Department of Radiology, Brigham and Women's Hospital,

Boston, MA, USA

e-mail: jstauss@partners.org

C. Franzius

Department of Nuclear Medicine, University Hospital Muenster, Muenster, Germany

e-mail: christiane.franzius@t-online.de

C. Franzius

MR and PET/CT-Centre Bremen-Mitte,

Bremen, Germany

T. Pfluger $\cdot$ K. Hahn

Department of Nuclear Medicine,

Ludwig-Maximilians-University,

Munich, Germany

K. U. Juergens

Department of Clinical Radiology, University Hospital Muenster,

Muenster, Germany

L. Biassoni $\cdot$ J. Begent

Great Ormond Street Hospital for Children NHS Trust,

London, UK
R. Kluge

Department of Nuclear Medicine, University of Leipzig, Leipzig, Germany

H. Amthauer $\cdot$ T. Voelker

Campus Virchow-Klinikum, Charité-Universitätsmedizin Berlin, Berlin, Germany

\section{Højgaard}

Department of Clinical Physiology and Nuclear Medicine and PET and Cyclotron Unit,

Rigshospitalet, Copenhagen University Hospital,

Copenhagen, Denmark

S. Barrington

PET Imaging Centre at St. Thomas',

Guy's, King's and St. Thomas' School of Medicine,

London, UK

S. Hain

University College Hospitals NHS Trust,

London, UK

T. Lynch

Royal Victoria Hospital,

Belfast, UK 